\title{
Structure and characterization of a new organic crystal for optical limiting applications, isonicotinamide bis-p-aminobenzoic acid
}

\author{
${ }^{1}$ Vijayalakshmi A., ${ }^{2}$ Vidyavathy Balraj and ${ }^{3}$ Vinitha G. \\ ${ }^{1}$ Department of Chemistry, RMK. Engineering College, Kavaraipettai 601206, India \\ vidyavathybalraj@gmail.com \\ ${ }^{2}$ Department of Chemistry, Velammal Engineering College, Chennai 600066, India \\ ${ }^{3}$ Department of Physics, VIT University, Chennai-600127, India
}

Received: 23.05 .2016

\begin{abstract}
A new organic nonlinear optical single crystal, isonicotinamide bis-paminobenzoic acid (INBAB), is grown from methanol solution using a slow evaporation solution technique. INBAB belongs to a monoclinic system with the space group $\mathrm{P} 2{ }_{1} / \mathrm{n}$. Its relative optical transmittance and optical band gap are found to be $58 \%$ and $3.4 \mathrm{eV}$, respectively. INBAB is thermally stable up to $147^{\circ} \mathrm{C}$. The laser-induced surface damage threshold for our crystal is equal to $1.2 \mathrm{GW} / \mathrm{cm}^{2}$ for the $1064 \mathrm{~nm} \mathrm{Nd:YAG} \mathrm{laser} \mathrm{radiation.} \mathrm{The} \mathrm{nonlinear} \mathrm{refractive} \mathrm{index,} \mathrm{the} \mathrm{absorption}$ coefficient and the third-order nonlinear susceptibility of our crystal are determined using a $Z$-scan technique. The material demonstrates optical-limiting behaviour up to the input irradiance of around $5.63 \mathrm{~mW}$.
\end{abstract}

Keywords: optical materials, nonlinear susceptibility, laser damage threshold, optical limiting

PACS: 42.25.Bs, 42.65.An

UDC: 535.3

\section{Introduction}

In the recent decades organic nonlinear optical materials have attracted much attention of researchers owing to their relatively high nonlinearity and fast response. Harmonics generation, frequency doubling and mixing, optical parametric oscillation and optical limiting are among their promising applications in photonics. It is known that the character of movement of delocalized $\pi$-electron cloud from a donor to acceptor in aromatic organic species can result in various nonlinear optical compounds. Notice that zeroing of even-order susceptibilities of centrosymmetric media, which is often the case of organic materials, does not imply that those materials cannot be applied in nonlinear optics, especially if their response is fast and the damage threshold with respect to laser intensity not too low.

Organic isonicotinamide includes amine and pyridyl groups which are capable to form a plethora of well predictable hydrogen bonding arrangements. As a result, it is often used in crystal engineering. Isonicotinamide displays polymorphism in its solid state due to flexible hydrogen bonding capability [1-5]. The interest of researchers in the field of nonlinear optics in isonicotinamide has been constantly progressing. In particular, a new organic material, (bis)isonicotinamide perchlorate, has been recently reported in Ref. [6]. p-aminobenzoic acid is an achiral compound; it is not dipolar because the aromatic- $\mathrm{NH}_{2}$ group is a weak base that cannot neutralize the $\mathrm{COOH}$ group. This acid can easily form many different compounds by giving its protons to acceptor groups in basic molecules through hydrogen-bond interactions. In this way, a new organic compound, isonicotinamide bis-p-aminobenzoic acid or simply INBAB, has been 
engineered, which is stabilized through the $\mathrm{N}-\mathrm{H} \ldots \mathrm{O}$ and $\mathrm{C}-\mathrm{H} \ldots \mathrm{O}$ hydrogen-bond interactions. To ascertain the potential use of INBAB crystals in laser-based devices, knowledge of their laser damage threshold, thermal stability, nonlinear refractive index, third-order nonlinear optical susceptibility and optical limiting behaviour are extremely important. In the present work we report on growth, crystal structure, thermal behaviour, as well as linear and nonlinear optical properties and laser damage threshold for the INBAB crystals.

\section{Experimental}

\subsection{Synthesis and crystal growth}

p-aminibenzoic acid (Alfa Aesar, 99\%) and isonicotinamide (Alfa Aesar, 99\%) were separately dissolved in a methanol solvent according to their equimolar ratio. After a clear solution had been obtained, isonicotinamide was added in a drop-wise manner into the acidic solution. This resulted in a sudden change of its state, with light-brownish precipitate. Then the resultant product was dissolved in the same solvent and stirred for $3 \mathrm{~h}$.

The solubility of INBAB in methanol solvent was assessed at different temperatures ranging from 30 to $45^{\circ} \mathrm{C}$. The saturated solution was prepared at those temperatures and the solubility of INBAB was estimated gravimetrically. The solubility curve for INBAB thus obtained is shown in Fig. 1. According to those data, a growing solution was prepared and filtered, followed by covering the solution with a perforated polythene sheet to restrict abundant evaporation. The filtered solution was allowed to evaporate at the temperature $33^{\circ} \mathrm{C}$. After 20 days had passed, a rod-like crystal was obtained as shown in Fig. 2.

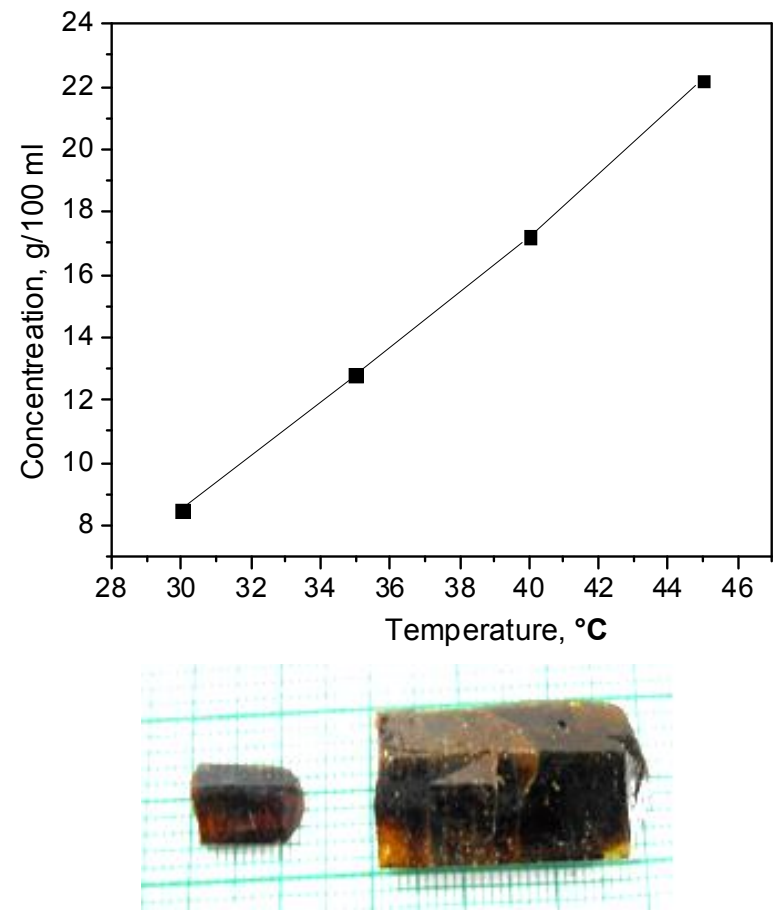

Fig. 1. Solubility of INBAB in methanol solvent.

Fig. 2. INBAB crystals grown at our laboratory.

\section{Results and discussion}

\subsection{X-ray diffraction analysis}

The crystal structure of INBAB was determined using a standard single-crystal X-ray diffraction analysis. The intensity data was collected on a Bruker kappa APEXII single-crystal X-ray 
diffractometer. We used a graphite-monochromated $\mathrm{MoK}_{\alpha}$ radiation $(\lambda=0.71073 \AA)$ at $293 \mathrm{~K}$ [7].

The structure was solved using a direct method and refined with a full-matrix least-squares technique, basing on a SHELXL 97 program package [8]. The crystal structure of our compound is shown in Fig. 3. It crystallizes in the centrosymmetric monoclinic space group $\mathrm{P} 2{ }_{1} / \mathrm{n}$, with the

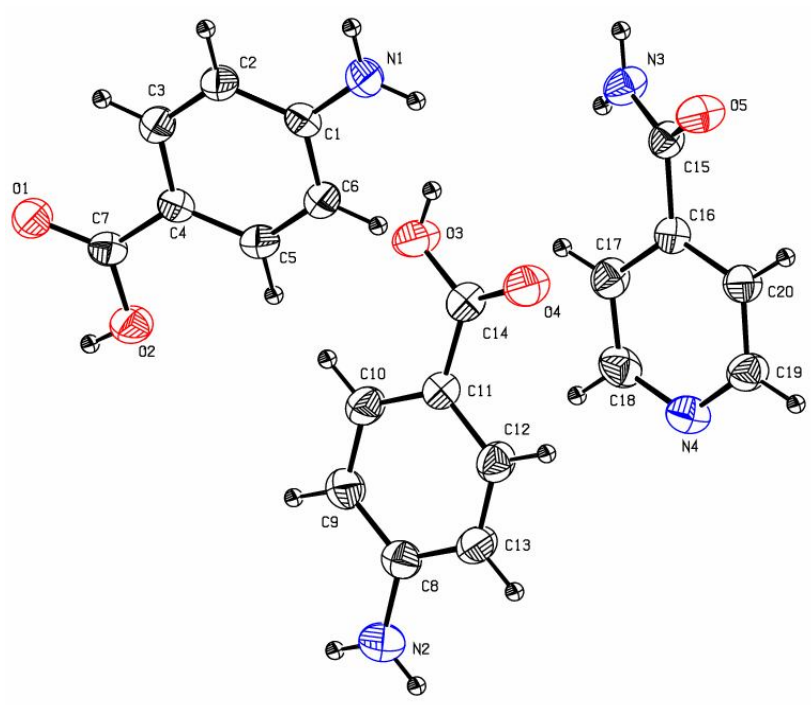

Fig. 3. ORTEP diagram obtained for INBAB.

following unit cell parameters: $a=17.2283(13) \AA, \quad b=5.1507(4) \AA, \quad c=22.6787(15) \AA$, $V=1880.8(2) \AA^{3}$, and $\alpha=\gamma=90^{\circ}, \beta=110.840(2)^{\circ}$ (see Table 1). The molecular packing of INBAB is stabilized by the intermolecular $\mathrm{N}-\mathrm{H} \ldots \mathrm{O}$ and $\mathrm{O}-\mathrm{H} . . . \mathrm{O}$ hydrogen bonds (see Fig. 4). The isonicotiamide ring ( $\mathrm{N} 4 / \mathrm{C} 16-\mathrm{C} 20)$ adopts a linear conformation with the $\mathrm{C} 20$ atom having a maximum deviation, 0.0066(19) $\AA$. The both of amino-acid molecules also form a planar

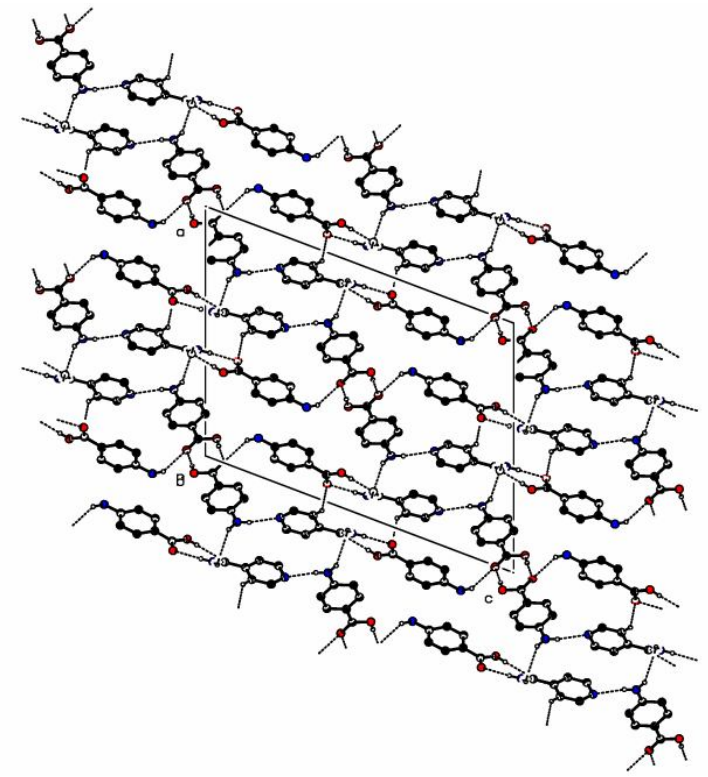

Fig. 4. Packing diagram obtained for INBAB. construction, with the $\mathrm{C} 1$ and $\mathrm{C} 11$ atoms having the maximum deviations $-0.0096(19)$ and $-0.0092(19) \AA$, respectively. The mean plane of the amino-benzoic acid ring 1 (C1-C6) makes the dihedral angle $19.91(10)^{\circ}$ with the amino benzoic acid ring 2 (C8C13). Furthermore, it makes the dihedral angle $19.06(9)^{\circ}$ with the isonicotiamide ring. The dihedral angle between the amino-benzoic acid ring 2 and the isonicotiamide ring is equal to $1.50(10)^{\circ}$. The intermolecular hydrogen bond $\mathrm{O} 2-$ $\mathrm{H} 2 \mathrm{C} \ldots \mathrm{O} 1$ stabilizes the crystal structure, forming $\mathrm{R}_{2}^{2}(8)$ dimmers. Moreover, the crystal structure is stabilized by the hydrogen bonds $\mathrm{N}-\mathrm{H}$... $\mathrm{O}$ and $\mathrm{C}-\mathrm{H} . . . \mathrm{O}$, which generate a three-dimensional network. 


\subsection{Thermal studies}

We carried out differential thermal (DT) and thermogravimetric (TG) analyses on INBAB, using a NETZSCH STA 409 instrument. The heating process started from $34^{\circ} \mathrm{C}$ and finished at $500^{\circ} \mathrm{C}$, with the heating rate of $10^{\circ} \mathrm{C} / \mathrm{min}$. The TG/DT diagram is depicted in Fig. 5. The material is thermally stable and moisture-free up to $147^{\circ} \mathrm{C}$. Three stages of weight-loss pattern are observed on the TG curve between 180 and $500^{\circ} \mathrm{C}$. They are due to degradation of the INBAB compound into gaseous products. As there is no weight loss up to $147^{\circ} \mathrm{C}$, the crystal is evidently free from solvent molecules. One can also conclude that a sharp endotherm located at $147^{\circ} \mathrm{C}$ on the DT curve originates from the melting point of INBAB. Finally, all the endotherms appearing on the DT curve are matched with the TG degradation data. Thus, the above TG/DT analyses confirm that the INBAB material decomposes above $171^{\circ} \mathrm{C}$. Moreover, one can readily apply our material below $147^{\circ} \mathrm{C}$.

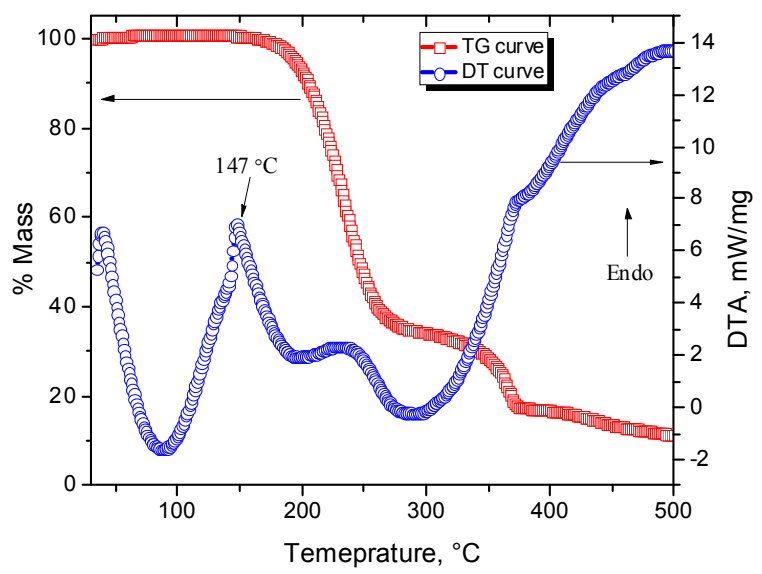

Fig. 5. TG/DT curves obtained for INBAB.

\section{3. $U$ V-Vis-NIR spectral studies}

We recorded the UV-Vis-NIR optical transmission spectrum for the INBAB sample with the thickness $1.5 \mathrm{~mm}$ in the wavelength range $190-900 \mathrm{~nm}$, using a Labindia $3032 \mathrm{UV}-\mathrm{Vis}-\mathrm{NIR}$

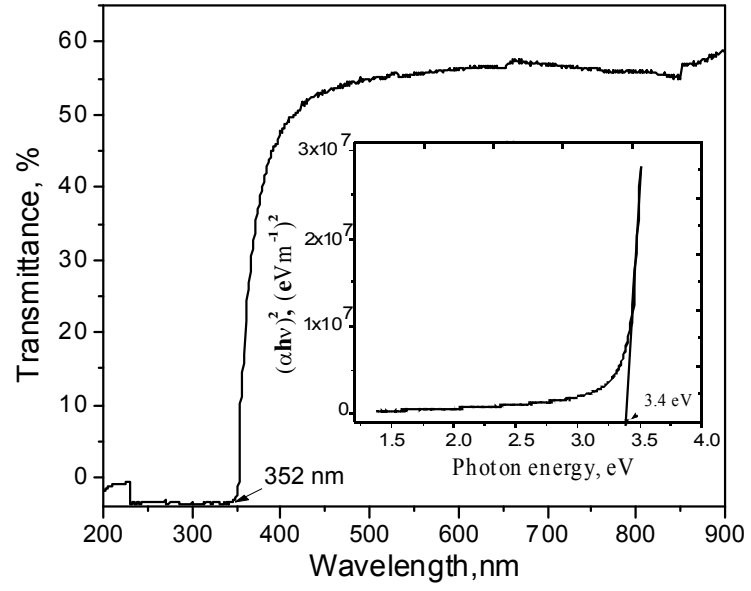

Fig. 6. UV-Vis-NIR transmission spectrum for the INBAB crystals. Inset shows the Tauc's plot. spectrophotometer. Our experiments demonstrate that the INBAB crystals reveal the relative optical transmittance as high as $58 \%$ up to $900 \mathrm{~nm}$. As seen from Fig. 6, the lower cut-off wavelength amounts to $352 \mathrm{~nm}$. The optical absorption is caused by direct transitions $\mathrm{n} \rightarrow \pi^{*}$ of electrons from non-bonding ' $n$ ' orbital to anti-bonding ' $\pi$ ' orbitals denoted as $\pi^{*}$. As illustrated in Fig. 6, inset, the optical band gap calculated using a so-called Tauc's plot is equal to $3.4 \mathrm{eV}$ [9]. 


\subsection{Laser-induced optical damage}

To measure laser-damage threshold for our INBAB crystals, we used the laser with the pulse width $10 \mathrm{~ns}$, the repetition rate $10 \mathrm{~Hz}$ and the fundamental wavelength $1064 \mathrm{~nm}$. The laser beam with the diameter of $1 \mathrm{~mm}$ was focused on the sample. The sample was placed at the focus of a planoconvex lens (the focal length $30 \mathrm{~cm}$ ). The energy of laser pulses was varied using attenuator that included a polarizer and a half-wave plate. The pulse energy of each laser shot was measured with a combination of a phototube and an oscilloscope. Finally, the surface damage threshold was calculated using the following relation for the power density $P_{d}$ :

$$
P_{d}=E / \tau \pi r^{2} .
$$

Here $E$ is the input energy in $\mathrm{mJ}, \tau$ the pulse width in ns and $r$ the radius of the spot in $\mathrm{mm}$. As a result, the laser damage threshold for the INBAB crystals is found to be $1.2 \mathrm{GW} / \mathrm{cm}^{2}$.

\subsection{Third-order nonlinear optical and optical limiting studies}

A Z-scan method represents an excellent tool for accurate measurements of the intensitydependent nonlinear refractive index, the nonlinear absorption coefficient and the third-order nonlinear optical susceptibility $\chi^{(3)}[10]$. The open- and closed-aperture Z-scans for INBAB were performed, using a $532 \mathrm{~nm}$ diode-pumped CW Nd:YAG laser (Coherent Compass TM215M-50). The laser was focused with a $3.5 \mathrm{~cm}$ focal-length lens. The laser beam waist at the focus was equal to $15.84 \mu \mathrm{m}$ and the Rayleigh length was $1.48 \mathrm{~mm}$. A $1 \mathrm{~mm}$-wide optical cell containing the INBAB sample in dimethylformamide was translated across the focal region along the axial direction (i.e., the direction of laser beam propagation).
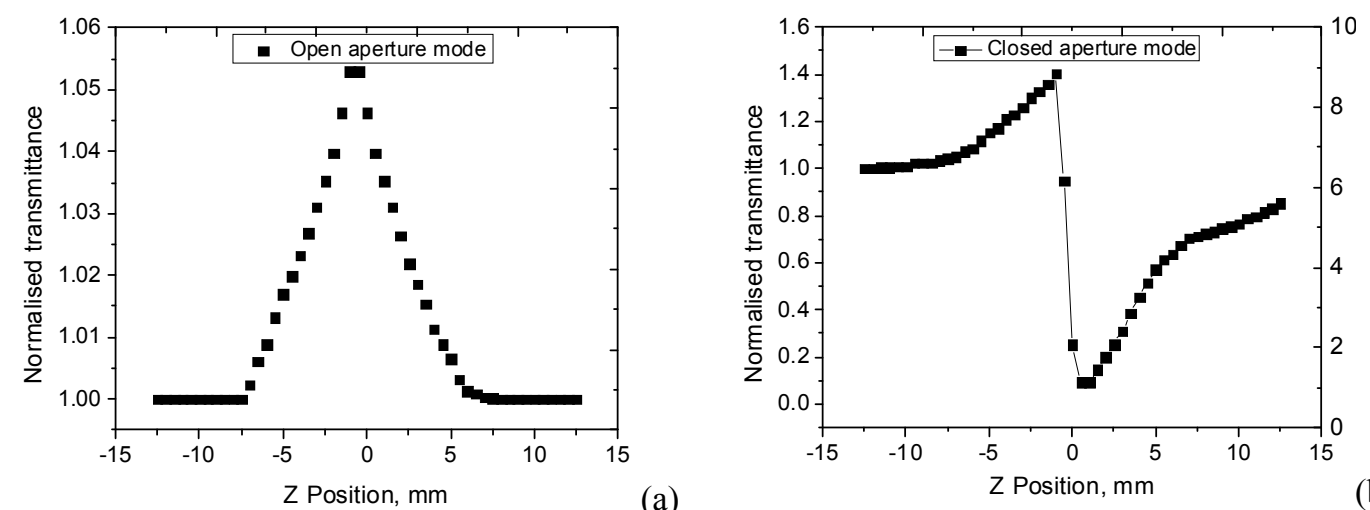

(a)

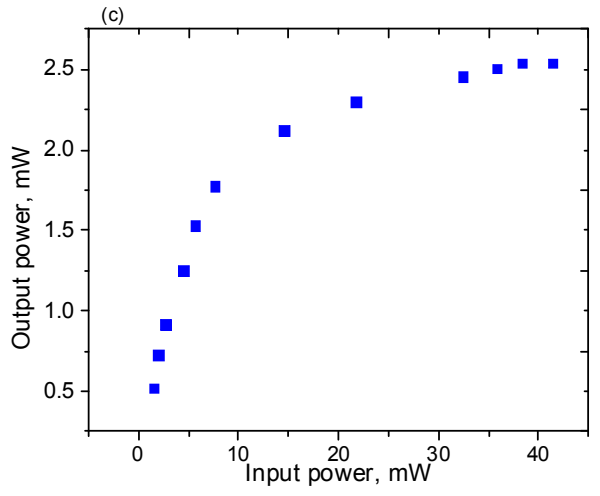

(c)

Fig. 7. Open-aperture (a), closed-aperture (b) and optical limiting (c) curves.

The experimental results collected by us indicate that the sample exhibits saturated absorption with a positive absorption coefficient $\beta$. The maximum transmittance at the focus 
$(Z=0)$ reveals a clear saturation of the absorption at high enough intensities. There is a maximum transmittance in the focus, or a 'peak', for the materials with saturable absorption, and a minimum transmittance in the focus, or a 'valley', for the materials with reverse saturable absorption. A peak seen on the open-aperture curve in Fig. 7a confirms that the multi-photon absorption effect occurs in INBAB. A peak followed by a valley in the closed-aperture mode of the $Z$-scan curve (see Fig. 7b) testifies a negative nonlinearity appearing due to self-defocusing effect. The third-order nonlinear optical parameters can be calculated using our data and standard equations presented, e.g., in Refs. [11-14]. The nonlinear refractive index $n_{2}$, the absorption coefficient $\beta$ and the thirdorder susceptibility $\chi^{(3)}$ values for the INBAB crystals are $7.41 \times 10^{-8} \mathrm{~cm}^{2} / \mathrm{W}, 0.04 \times 10^{-4} \mathrm{~cm} / \mathrm{W}$ and $4.75 \times 10^{-6}$ esu, respectively.

The optical limiting in INBAB was studied by varying systematically the input laser power. The corresponding output powers were measured with a photodetector. The optical limiting behaviour of the INBAB crystals is illustrated in Fig. 7c. One can see from Fig. 7c that the transmitted output power increases linearly with increasing input power up to the irradiance of $2 \mathrm{~mW}$. The transmitted power reaches a plateau with further increase in the input power and then saturates at a point defined as the limiting power. Hence, a maximum observed in the output power points to a clear limiting property. In other words, our crystals can be regarded as a suitable candidate for optical limiting applications.

\section{Conclusion}

In summary, a new organic compound, isonicotinamide bis-p-aminobenzoic acid, has been synthesized and grown using the slow evaporation method. We have determined its crystal structure basing on the single-crystal X-ray diffraction experiments. It follows from our UV-VisNIR spectral studies that INBAB manifests the optical transmittance close to $58 \%$ up to $900 \mathrm{~nm}$, with the lower cut-off wavelength as small as $352 \mathrm{~nm}$. The thermal behaviour of INBAB has been studied using the TG/DT analyses. The laser-induced surface damage threshold for our crystals is equal to $1.2 \mathrm{GW} / \mathrm{cm}^{2}$ at the Nd:YAG laser radiation wavelength $1064 \mathrm{~nm}$. The nonlinear refractive index $n_{2}$, the absorption coefficient $\beta$ and the third-order nonlinear susceptibility $\chi^{(3)}$ have been measured with the standard $Z$-scan technique. The optical limiting behaviour of the INBAB crystal found by us confirms that it represents a promising candidate for many optical limiting applications.

\section{References}

1. Chemla D S and Zyss J, Nonlinear optical properties of organic molecules crystals. Academic Press: New York (1987).

2. Meredith G R, Nonlinear optical properties of organic and polymeric materials (Ed. by D J Williams), ACS Symposium Series 223, American Chemical Society, Washington, DC (1983), pp. 27-56.

3. Freeman J L, Zhao Q, Zhang Y, Wang J, Lawsonb C M and Gray G M, 2013. Synthesis, linear and nonlinear optical properties of phosphonato-substituted bithiophenes derived from 2,2'biphenol. Dalton Trans. 42: 14281-14297.

4. Fellows S M and Prior T J, 2016. Crystal structure of 4-carbamoylpyridinium chloride. Acta Cryst. E. 72: 436-439.

5. Zyss J and Nicoud F, 1996. Status and perspectives for molecular nonlinear optics-from crystals to polymers and fundamentals to applications. Curr. Opin. Solid State Mater. Sci. 1: 533-546.

Ukr. J. Phys. Opt. 2016, Volume 17, Issue 3 
6. Syed Suresh Babu K, Peramaiyan G, NizamMohideen M and Mohan R, 2015. Crystal structure, growth and characterization of semiorganic nonlinear optical bis(isonicotinamide)perchlorate monohydrate (BINPM). J. Therm. Anal. Calorim. 120: 13371345.

7. Bruker APEX2, SAINT, XPREP \& SADABS.2004. Bruker AXS Inc, Madison, Wisconsin, USA.

8. Sheldrick GM, 2008. A short history of SHELX. Acta Cryst. A. 64: 112-122.

9. Tauc J, Grigorovici R and Vancu A, 1966. Optical properties and electronic structure of amorphous germanium. Phys. Stat. Solidi B. 15: 627-637.

10. Sheik-Bahae M, Said A A, Wei T, Hagan D J and Van Stryland E M, 1990. Sensitive measurement of optical nonlinearities using a single beam. IEEE J. Quant. Electron. 26: 760 769.

11. Dhanaraj P V, Rajesh N P, Vinitha G and Bhagavannarayana G, 2011. Crystal structure and characterization of a novel organic optical crystal: 2-Aminopyridinium trichloroacetate. Mater. Res. Bull. 46: 726-731.

12. Anandha Babu G and Ramasamy P, 2011. Growth and characterization of 2-amino-4picolinium toluene sulfonate (2A4PTS). Spectrochim. Acta A. 82: 521-526.

13. Dhanaraj P V, Rajesh N P, Kalyana Sundar J, Natarajan S, Vinitha G and Bhagavannarayana G, 2011. Crystal structure and characterization of novel organic nicotinium trifluoroacetate single crystals. Mater. Chem. Phys. 129: 457-463.

14. Cassano T, Tommasi R, Ferrara M, Babudri F, Farinola G M and Naso F, 2001. Substituentdependence of the optical nonlinearities in poly(2,5-dialkoxy-p-phenylenevinylene) polymers investigated by the Z-scan technique. Chem. Phys. 272: 111-118.

Vijayalakshmi A., Vidyavathy Balraj and Vinitha G. 2016. Structure and characterization for optical limiting applications of a new organic crystal - isonicotinamide bis-p-aminobenzoic acid. Ukr.J.Phys.Opt. 17: 98 - 104

Анотація. Новий органічний нелінійно-оптичний монокристал ізонікотинамід біс-р-амінобензойна кислота (INBAB) вирощено з метанолового розчину із використанням методу повільного випарювання розчину. INBAB належить до моноклінної системі з просторовою групою P21/n. Його відносне оптичне пропускання $i$ оптична ширина забороненої зони дорівнюють відповідно 58\% i 3,4 еВ. Сполука INBAB термічно стабільна аж до $147^{\circ} \mathrm{C}$. Виміряний для кристала поріг лазерно-індукованого пошкодження поверхні складає

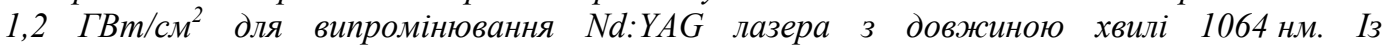
використанням методики Z-сканування визначено нелінійний показник заломлення $i$ коефіцієнт поглинання, а також нелінійну сприйнятливість третього порядку. Виявилося, щзо матеріал виявляє оптичне обмеження для вхідного опромінення аж до 5,63 мВт. 